\title{
Clinical study of tubectomy and it's complications
}

\author{
Fasiha T. Abdul Aziz, Kruthi R.*
}

\begin{abstract}
Department of Obstetrics and Gynecology, Dr Shankarrao Chavan Government Medical College, Vishnupuri, Nanded,
\end{abstract} Maharashtra, India

Received: 09 April 2020

Accepted: 06 May 2020

\section{*Correspondence:}

Dr. Kruthi R.,

E-mail: kruthir2@gmail.com

Copyright: ( $)$ the author(s), publisher and licensee Medip Academy. This is an open-access article distributed under the terms of the Creative Commons Attribution Non-Commercial License, which permits unrestricted non-commercial use, distribution, and reproduction in any medium, provided the original work is properly cited.

\begin{abstract}
Background: Tubectomy is most accepted method of contraception in India. Female sterilization may be performed in several ways such as abdominal tubal ligation, laparoscopic and hysteroscopic methods. Although considered as minor and safe procedure, complications leading to even death have been reported. So, this study was taken up to study complications of different types of tubal ligation. Objective of this study was to study complications of different types of tubal ligation.

Methods: This is a prospective analytical study over the period of 18 months. This study includes all cases that have reported or referred as female sterilization complication.

Results: At study institute both laparoscopic tubal ligation (TL) and abdominal tubal ligation are done. During the period of 18 months, 50 cases of tubectomy complications were noted at our institute, out of 40 cases $(80 \%)$ were of abdominal method and rest $10(20 \%)$ were of laparoscopic method. In 33 cases $(66 \%)$ sterilization was performed at primary health centre. 3 cases of death reported in this study.

Conclusions: At study institute both laparoscopic tubal ligation (TL) and abdominal tubal ligation are done. During the period of 18 months, 50 cases of tubectomy complications were noted at our institute, out of 40 cases $(80 \%)$ were of abdominal method and rest $10(20 \%)$ were of laparoscopic method. In 33 cases $(66 \%)$ sterilization was performed at primary health centre. 3 cases of death reported in this study.
\end{abstract}

Keywords: Abdominal tubal ligation, Laparoscopic tubal ligation, Prospective study, Sepsis

\section{INTRODUCTION}

Female sterilization or tubal ligation or tubectomy is the most accepted method of contraception in India. Female sterilization is one of the best and effective methods of contraception for women who have completed their family. In Asia, female sterilization rose from $34 \%$ in $1980-1984$ to $42-43 \%$ in $1985-2005 .{ }^{1}$ In contrast the share of female sterilization remained fairly level at 5-8\% in Sub-Saharan, Africa and the developed countries. According to National Family Health Survey-4 (2015$16), 36 \%$ of currently married women in the age group 15-49 years were sterilized which accounted for $66 \%$ of all the contraception use, making it a leading method of contraception (Figure 1). ${ }^{2}$ In the US, second leading method of contraception was female sterilization, used by 10.3 million women. Female sterilization is the leading method among women 35 years and older. ${ }^{3}$

Female sterilization can be carried out, at any of the following time, postpartum sterilization - done within seven days of delivery, caesarean tubal ligation - the two procedures are combined, interval ligation done six weeks after delivery, post-abortal ligation-immediately after evacuation of uterus after induced or incomplete abortion, gynaecological ligation-combined with gynaecological surgeries such as myomectomy or Fothergill's operation. Female sterilization may be performed in several ways such as abdominal tubal ligation, laparoscopic sterilization and hysteroscopic 
methods. Tubectomy during caesarean operation and abdominal tubal ligation are popular methods in developing countries where as laparoscopic sterilization and hysteroscopic tubal occlusion are the preferred methods in developed countries.

The World Health Organisation's (WHO) task force on female sterilization stated: The ideal female sterilization would involve a simple, easily learned, one-time procedure that could be accomplished under local anaesthesia and involve a tubal occlusion technique that caused minimum damage. The sterilization procedure should not only be safe and readily accessible but also have high efficacy rate, cost-effective, be culturally and personally acceptable.

Although considered as minor and safe procedure of permanent fertility control, complications leading to even death have been reported. In this study, authors have included intra-operative, immediate and late postoperative complications. Authors have tried to evaluate etiological factors and also preventive measures to reduce morbidity and mortality due to female sterilization procedures specially in developing country like India where tubectomy complication is a genuine medical issue.

\section{METHODS}

This is a prospective analytical study conducted at study institute. It is a tertiary care institute with primary health centres attached to it. It is a referral hospital for both public and private health sectors. This study includes all cases that have reported or referred as female sterilization complication to department of obstetrics and gynecology, Government Medical College and hospital. Study protocol was approved by ethics committee. 18 months study duration.

\section{Inclusion criteria}

- Postpartum and interval sterilizations with perioperative (during and immediately after surgery) and late post-operative complications are included in this study

- Post-partum - the patients who underwent the procedure after the birth of the baby were taken as postpartum sterilization. Postpartum sterilization ideally is done before the uterus returns to its normal location, usually within a few hours or days following delivery. For women who had a caesarean delivery, it is done right after the baby is born

- Interval-patients who underwent the procedure 6 weeks after delivery were taken as interval sterilization

- For abdominal method, Pomeroy's technique was used

- For laparoscopic sterilization, silastic bands were used.

\section{Exclusion criteria}

- Sterilizations with medical termination of pregnancy

- Sterilizations with caesarean section.

\section{Pomeroy's technique}

- A loop of the proximal portion of the tubal ampulla is elevated to reveal the vascular supply of the mesosalpinx.

- A strand of absorbable suture material is used to bilaterally ligate the tube and simultaneously provide hemostasis.

- A hemostat is placed on the suture strands immediately distal to the knot to prevent the tube from retracting into the abdomen. The open blade of the metzenbaum scissors is used to pierce the mesosalpinx and approximately $1 \mathrm{~cm}$ of the tube is excised.

- The end result following dissolution of the absorbable suture material is return of the proximal and distal portions of the tube to their normal anatomic position.

Information has been collected from cases included in this study at study institute after approval of ethical committee. A case of tubal ligation complication was assessed to collect information regarding.

- $\quad$ Place of tubectomy

- Timing of tubectomy

- Type of tubectomy.

Both general and systemic examination of a case was done to assess type of complication i.e., whether Intra operative, Immediate or Late post- operative complications. Routine lab investigations of all cases were done to identify any high-risk factors like anaemia, infection etc. In case of intra operative complications like bowel injury, bladder injury assistance was taken from surgery department in the management of the cases. After thorough history taking, examination and routine work up of cases management was started accordingly.

Complications were notified to head of the department, district health officer, civil surgeon as tubectomy is included under national programme. Cases were further divided depending on medical or surgical intervention needed after expert opinion. Morbidity, was assessed depending on length of stay and further treatment needed either medical or surgical. The risk factors, different type of complications and their management were compared using graphs and charts.

\section{Statistical analysis}

Statistical analysis was conducted using SPSS 20.0 software package statistical significance was determined using appropriate statistical tests. 


\section{RESULTS}

At this study institute, tubal ligation is carried out as elective procedure. Both laparoscopic tubal ligation and abdominal tubal ligation are done. Laparoscopic Tubal ligation is done more frequently than abdominal Tubal ligation. Method used for laparoscopic tubal ligation is silastic band application technique under general anaesthesia. Method used for abdominal tubal ligation is Pomeroy’s technique under IV general anaesthesia.

Table 1: Yearly statistics (October 2016 -November 2018).

\begin{tabular}{|llll|}
\hline & $\begin{array}{l}\text { No. of } \\
\text { lap TL }\end{array}$ & $\begin{array}{l}\text { No. of } \\
\text { abdo TL }\end{array}$ & Total \\
\hline 2016 (from October) & 43 & 2 & 45 \\
\hline 2017 & 262 & 14 & 276 \\
\hline 2018 (till November) & 190 & 9 & 199 \\
\hline
\end{tabular}

Yearly statistics of different methods are mentioned below (October 2016-November 2018) (Table 1).

During the period of 18 months, 50 cases of tubectomy complications were noted at study institute which includes both referred cases and complications at study hospital.

Table 2: Place of sterilization.

\begin{tabular}{|lll|}
\hline Place of TL done & No. of cases & $\%$ of cases \\
\hline PHC & 33 & $66 \%$ \\
\hline RH & 11 & $22 \%$ \\
\hline TH & 6 & $12 \%$ \\
\hline Total & 50 & 100 \\
\hline
\end{tabular}

Table 3: Type of sterilization.

\begin{tabular}{|lll|}
\hline Type of TL & No. of cases & \% of cases \\
\hline Lap TL & 10 & $20 \%$ \\
\hline Abdominal TL & 40 & $80 \%$ \\
\hline Total & 50 & $100 \%$ \\
\hline
\end{tabular}

Table 4: Timing of surgery - post-partum/interval.

\begin{tabular}{|lll|}
\hline Timing of TL & No. of cases & $\%$ of cases \\
\hline Post-partum TL & 6 & $12 \%$ \\
\hline Interval TL & 44 & $88 \%$ \\
\hline Total & 50 & $100 \%$ \\
\hline
\end{tabular}

Table 5: Type of management.

\begin{tabular}{|lll|}
\hline Type of intervention & $\begin{array}{l}\text { No. of } \\
\text { cases }\end{array}$ & $\%$ of cases \\
\hline Conservative management & 31 & $62 \%$ \\
\hline Minor surgical intervention & 6 & $12 \%$ \\
\hline Major surgical intervention & 13 & $26 \%$ \\
\hline Total & 50 & 100 \\
\hline
\end{tabular}

Depending on type of complication and further management needed patients were further classified. 31 cases $(62 \%)$ were managed with conservative management and rest cases needed surgical management. 13 cases $(26 \%)$ were managed with exploration and further surgical intervention depending upon intraoperative findings and 6 cases $(12 \%)$ needed minor procedures like resuturing (Table 5).

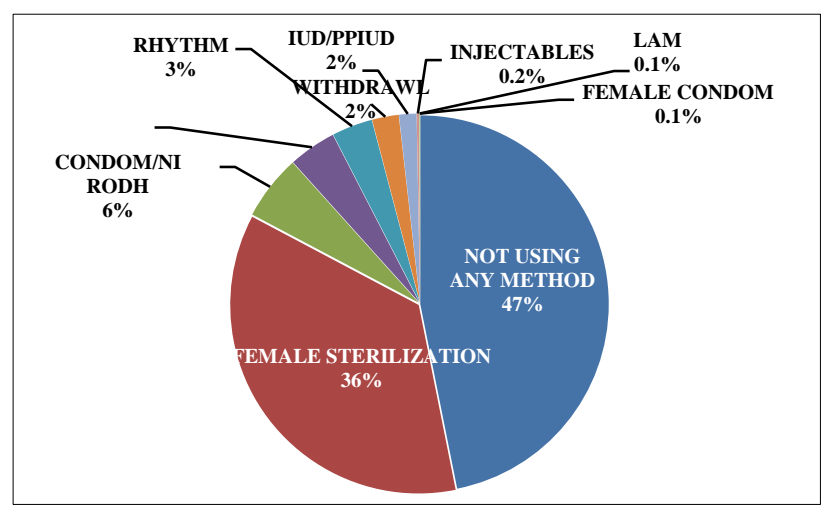

Figure 1: Contraceptive usage in married women in age group of 15-49 years (NFHS-4) National Family Health Survey-4.

Table 6: Type of complication.

\begin{tabular}{|lll|}
\hline Type of complications & $\begin{array}{l}\text { No. of } \\
\text { cases }\end{array}$ & $\%$ of cases \\
\hline Intra-op & 11 & $22 \%$ \\
\hline Immediate post op & 31 & $62 \%$ \\
\hline Late post op & 8 & $16 \%$ \\
\hline Total & 50 & $100 \%$ \\
\hline
\end{tabular}

Table 7: Type of intra op complications.

\begin{tabular}{|lll|}
\hline Type & No. of cases & $\%$ of cases \\
\hline Mesosalpingeal bleeding & 3 & $27.27 \%$ \\
\hline Bladder injury & 1 & $9.09 \%$ \\
\hline Bowel injury & 1 & $9.09 \%$ \\
\hline Tubal avulsion & 1 & $9.09 \%$ \\
\hline Adhesions & 1 & $9.09 \%$ \\
\hline Ovarian injury & 2 & $18.18 \%$ \\
\hline Uterine perforation & 2 & $18.18 \%$ \\
\hline Total & 11 & $100 \%$ \\
\hline
\end{tabular}

When place of sterilization is compared maximum number of cases (33) were operated at primary health centre (PHC) (66\%) followed by rural hospital (RH) (11) $(22 \%)$ and tertiary health centre (TH) (6) (12\%) (Table 2).

Based on type of sterilization method used, abdominal method applied in $40(80 \%)$ cases and laparoscopic method in $10(20 \%)$ cases (Table 3$)$. Based on timing of sterilization, 44 cases ( $88 \%$ ) were of interval type and 6 cases $(12 \%)$ were of post partal type (Table 4$)$. 
There were 31 cases $(62 \%)$ were immediate postoperative complications, 11 cases (22\%) were intra operative and 8 cases $(16 \%)$ were late post-operative complication (Table 6).

Table 8: Type of immediate post-operative complications.

\begin{tabular}{|lll|}
\hline Type & No. of cases & $\%$ of cases \\
\hline Wound infection/gape & 9 & $29.03 \%$ \\
\hline Burst abdomen & 4 & $12.9 \%$ \\
\hline Anaesthetic complications & 2 & $6.45 \%$ \\
\hline Convulsions & 1 & $3.22 \%$ \\
\hline Peritonitis (acute abdomen) & 2 & $6.45 \%$ \\
\hline Febrile illness & 3 & $9.67 \%$ \\
\hline Sepsis & 2 & $6.45 \%$ \\
\hline Others (cystitis, gastritis, pyosalphinx) & 8 & $25.8 \%$ \\
\hline Total & 31 & $100 \%$ \\
\hline
\end{tabular}

Table 9: Type of late post-operative complications.

\begin{tabular}{|lll|}
\hline Type & No. of cases & \% of cases \\
\hline Stich site granuloma & 2 & $25 \%$ \\
\hline Tubal ligation failure & 6 & $75 \%$ \\
\hline Total & 8 & $100 \%$ \\
\hline
\end{tabular}

Table 10: Distribution of patients by timings of sterilization in abdominal and laparoscopic sterilization.

\begin{tabular}{|llllllll|}
\hline Timings & Mini lap & $\%$ & Lap & $\%$ & Total & $\%$ \\
\hline Post-partum & 5 & $83.33 \%$ & 1 & $16.66 \%$ & 6 & $12 \%$ \\
\hline Interval & 35 & $79.54 \%$ & 9 & $20.45 \%$ & 44 & $88 \%$ \\
\hline Total & 40 & $80 \%$ & 10 & $20 \%$ & 50 & $100 \%$ \\
\hline
\end{tabular}

\section{DISCUSSION}

Female sterilization is the most requested contraceptive method worldwide and one of the most frequently performed elective, intra-abdominal surgical procedure in reproductive-age women.

At study institute both laparoscopic tubal ligation and abdominal tubal ligation are done laparoscopic tubal ligation is done more frequently than abdominal tubal ligation during the period of 18 months, 50 cases of tubectomy complications were noted at study institute. It includes all referred cases from government, private sectors and complications at study hospital.

In this study $66 \%$ cases of tubectomy complication were from PHC. This could be explained with Patil E et al, Hughes GJ and Stovall et al studies mentioning tubal sterilization is safe and highly effective in experienced trained hands regardless of approach and method of occlusion. ${ }^{4-6}$

When type of sterilization was compared $80 \%$ of complication cases were of abdominal tubal ligation, where laparoscopic tubal ligation only $20 \%$ as per Table
3 which is in contrast to previous studies of Kavita M et al and Mumford SD et al where surgical complication rate is found to be higher with laparoscopic tubal ligation and Patil E et al, Chick PH et al, Pati $\mathrm{S}$ et al with no much of difference in complication rates in two., ${ }^{4,-10}$

Time of surgery when discussed authors had $88 \%$ of complication cases of interval tubal ligation with only $12 \%$ of puerperal tubal ligation which is contrast to Patil $\mathrm{E}$ et al with postpartum and interval tubal ligation both found to be equally safe. ${ }^{4}$

Out of 50 complications, 31 cases $(62 \%)$ were managed with conservative management and rest cases needed surgical management. 13 cases $(26 \%)$ were managed with exploration and further surgical intervention depending upon intra-operative findings and 6 cases (12\%) needed minor procedures like resuturing. According to cochrane review, major morbidity seems to be a rare outcome for laparoscopy and abdominal tubal ligation. ${ }^{11}$

In this study, there were $11(22 \%)$ intra operative complications, 6 complications seen in abdominal method and 5 in laparoscopic method. Cases of mesosalpingeal bleeding were managed immediately by 
cauterization of bleeder intra-operatively. Klarke $\mathrm{M}$ et al, showed $1.4 \%$ of patients developed mesosalpinx tear during laparoscopic sterilization and required laparotomy to control bleeding from mesosalpinx tear. ${ }^{12}$ Major surgical interventions were managed with the help of department of surgery. 1 case of bowel injury required primary closure with colostomy of descending colon. 1 case had bladder injury and managed with bladder suturing.

A case of tubal avulsion was referred from periphery which was procedure related complication in abdominal method for which exploratory laparotomy was done at study institute and respective side salpingectomy was done. Two cases of uterine perforation noted in laparoscopic method. One which was caused due to uterine manipulator was managed conservatively intra operatively. In other case perforation caused at the time of inserting trocar in laparoscopic method, patient expired because of vasovagal attack.

There were 31 (62\%) immediate post-operative complications, 29 complications were seen in abdominal method and 2 in laparoscopic method. 7 cases of wound gape/infection were seen in abdominal method and 2 in laparoscopic method. 7 had resuturing of surgical wound. 4 cases of burst abdomen seen in abdominal method which were referred from periphery to study institute. The cases of burst abdomen were operated with the help of surgery department. This was because of faulty surgical procedures at periphery and improper preoperative work up of the patient. Three cases $(6 \%)$ of death were reported in this study in post-operative period, reason of two cases being infection (septicemia) seen in abdominal method which is comparable to Pulla P study of 13 cases of death in sterilization camps in Chhattisgarh India, all were because of septicemia due to poor hygiene during surgery.

The postmortem examinations of seven of the women indicated towards septicemia, which can result from poor hygiene during surgery. ${ }^{13}$ This can also be compared to Strauss LT et al with 55 sterilization deaths from 80 countries causes being infection, anesthesia or haemorrhage and contrast with Lawrie TA et al study of RCT where no death or major morbidity reported. ${ }^{13-15,19}$ Third death was because of vasovagal attack seen during insertion of trocar in laparoscopic method. Two anesthetic complications were noted which was managed conservatively.

There were 8 cases $(16 \%)$ of late post-operative complications, 7 were due to abdominal method and one due to laparoscopic method. 6 cases of tubal ligation failure noted, 5 were of abdominal method and 1 of laparoscopic method. Mumford SD et al, in their study compared abdominal and laparoscopic tubectomy for tubal sterilization from 23 countries. Number of cases who underwent laparoscopy with occlusion by the tubal ring was 7053, and abdominal tubal ligation with occlusion by the Pomeroy technique was 5081 cases. The failure rate was $0.60 \%$ for laparoscopy and 0.30 per 100 women for abdominal tubal ligation. In abdominal tubal ligation, the surgical complication rate $(0.79 \%)$ is less when compared to laparoscopic sterilization (2.04\%), whereas the technical failure rate was double that laparoscopic sterilization. The preference for abdominal tubal ligation over laparoscopy procedure was noted in this study. ${ }^{16}$

Most of cases of surgical complications had history of previous surgery or tuberculosis and many of medical complications were present before surgery and were not assessed properly before procedure. Important risk factors for complications included obesity greater than $12 \%$ of ideal body weight, diabetes, cigarette smoking, previous abdominal or pelvic surgery, and a history of pelvic inflammatory disease. ${ }^{17,18}$

Guidelines are given in Reference manual for female sterilization. November 2014. Family planning division, Ministry of Health and Family Welfare, Government of India regarding eligibility criteria for case selection, clinical assessment, anesthesia, prevention of infection, surgical procedure, post-operative care to reduce sterilization related morbidity and mortality with special emphasis on training in female sterilization and management of complications. ${ }^{19}$

\section{CONCLUSION}

- Female sterilization is the most popular method of contraception in India.

- From this study authors can conclude that laparoscopic method is commonly used for tubal ligation at study institute.

- From the above study authors came to the conclusion that tubectomy complications are common in abdominal method.

- Failure in assessing fitness of patient as per standard medical norms in form haemoglobin status, preoperative cough or febrile illness may result in complications of sepsis and burst abdomen.

- PHC's and camps follow abdominal method for tubal ligation which is associated with more complications than laparoscopic tubal ligation.

- Tubectomy is safe procedure in trained hands but complications can happen and many of them are preventable with proper screening and selection of cases with proper evaluation before surgery.

- There is a need to have proper training in sterilization and to stick to standards of sterilization procedure to minimize chances of complications.

- Sepsis is a major cause of death and asepsis could be compromised when female sterilization is done in large numbers in camps. Hence target related approach towards female sterilization should be avoided. 
Funding: No funding sources

Conflict of interest: None declared

Ethical approval: Not required

\section{REFERENCES}

1. Jain R, Muralidhar S. Contraceptive methods: needs, options and utilization. J Obstet Gynecol India. 2012;61:626-34.

2. International Institute for Population Sciences (IIPS) and ICF 2017. National Family Health Survey (NFHS-4) Volume I. India: Mumbai: IIPS; 2015-16, 2017. Available at: http://rchiips.org/nfhs/NFHS4Reports/India.pdf. Accessed on $10^{\text {th }}$ March 2020.

3. Mosher WD. Use of contraception and use of family planning services in the United States, 1982-2002. US Department of Health and Human Services, Centers for Disease Control and Prevention, National Center for Health Statistics; 2004.

4. Patil E, Jensen JT. Update on permanent contraception options for women. Curr Opin Obstet Gynecol. 2015;27(6):465-70.

5. Stovall TG, Ling FW, Henry GM, Ryan GM. Method failures of laparoscopic tubal sterilization in a residency training program. J Reprod Med. 1991;36:283-6.

6. Hudges GJ. Sterilization failure. $\mathrm{Br}$ Med J. 1977;2:1337-9.

7. Mahadevappa K, Prasanna N, Channabasappa RA. Trends of various techniques of tubectomy: a fiveyear study in a tertiary Institute. J Clin Diagn Res. 2016;10(1):QC04-QC07.

8. Mumford S, Bhiwandiwala P. Laparoscopic and minilaparotomy female sterilisation compared in 15 167 cases. Lancet Contracept. 1980;316(8203):106670.

9. Chick PH, Frances M, Paterson PJ. A comprehensive review of female sterilisation-tubal occlusion methods. Clin Reprod Fertil. 1985;3(2):81-97.

10. Pati S, Cullins V. Female sterilization. Evidence. Obstet Gynecol Clin North Am. 2000;27(4):859-99.
11. World Health Organization, Task Force on Female Sterilization, Special programme of Research, Development and Research Training in Human Reproduction. Minilaparotomy or laparoscopy for sterilization. Am J Obstet Gynecol. 1982;143:64552.

12. Klaerke M, Nielsen JEB, Vilsgaard K. Laparoscopic sterilization with the falope-ring technique in the puerperium. Acta Obstetricia et Gynecologica Scandinavica. 1986;65:99-101.

13. Pulla $P$. Why are women dying in India's sterilisation camps? BMJ. 2014;349.

14. Lawrie TA, Kulier R, Nardin J. Techniques for the interruption of tubal patency for female sterilization. Cochrane Database Syst Rev. 2015;9:CD003034.

15. Strauss LT, Huezo CM, Kramer DG, Rochat RW, Senanayake P, Rubin GL. Sterilization-associated deaths: a global survey. Int J Gynaecol Obstet. 1984;22(1):67-75.

16. Mumford SD, Bhiwandiwala PP, Chi IC. Laparoscopic and minilaparotomy female sterilization compared in 15167 cases. Lancet. 1980;2(8203):1066-70.

17. Layde PM, Peterson HB, Dicker RC, DeStefano F, Rubin GL, Ory HW. Risk factors for complications of interval tubal sterilization by laparotomy. Obstet Gynecol. 1983;62(2):180-4.

18. Huggins GR, Sondheimer SJ. Complications of female sterilization: immediate and delayed. Fertil Steril. 1984;41(3):337-55.

19. Reference manual for female sterilization. Family planning division, Ministry of Health and Family Welfare, Government of India; 2014.

Cite this article as: Aziz FTA, Kruthi R. Clinical study of tubectomy and it's complications. Int J Reprod Contracept Obstet Gynecol 2020;9:2550-5. 